\title{
Caspase-independent programmed cell death with necrotic morphology
}

\author{
Chifumi Kitanaka*,1 and Yoshiyuki Kuchino*,1,2 \\ ${ }^{1}$ Biophysics Division, National Cancer Research Institute, 5-1-1 Tsukiji, \\ Chuo-ku, Tokyo 104-0045, Japan \\ 2 CREST (Core Research for Evolutional Science and Technology), Japan \\ Science and Technology Corporation, 4-1-8 Honcho, Kawaguchi, Saitama \\ 332-0012, Japan \\ * corresponding authors: Chifumi Kitanaka and Yoshiyuki Kuchino, \\ tel: +81 033542 2511; fax: +81 033542 1369; \\ e-mail: ckitanak@ncc.go.jp and ykuchino@ncc.go.jp
}

Received 1.03.99; accepted 23.03.99

Edited by M. Piacentini

\begin{abstract}
Cell death is generally classified into two large categories: apoptosis represents active, programmed cell death, while necrosis represents passive cell death without underlying regulatory mechanisms. Recent progress revealed that caspases, a family of cysteine proteases, play a central role in the regulation of apoptosis. Unexpectedly, however, caspase inhibition occasionally turns the morphology of programmed cell death from apoptotic into necrotic without inhibiting death itself. In this article, we review different models of caspase-independent programmed cell death showing necrotic-like morphology, including our Rasmediated caspase-independent cell death. Based on these findings, we suggest the existence of a necrotic-like cell death regulated by cellular intrinsic death programs distinct from that of apoptosis. Even though type 2 physiological cell death, or autophagic degeneration, has been recognized as a necrotic-like programmed cell death for a long time, the underlying molecular mechanisms have not been identified despite its physiological significance. This has been in part due to the previous absence of adequate caspase-independent cellular models to study, recent efforts may now help to elucidate these mechanisms.
\end{abstract}

Keywords: apoptosis; necrosis; type 2 cell death; autophagic degeneration; caspase-independent; Ras

Abbreviations: $\mathrm{mCCCP}, \mathrm{m}$-chlorocarbonylcyanide phenylhydrazone; CTL, cytotoxic T lymphocyte; IGF, insulin-like growth factor; JNK, Jun N-terminal kinase; PI3K, phosphatidyl inositol 3-OH kinase; PPIX, protoporphyrin IX; TNF, tumor necrosis factor

\section{Introduction}

In the course of morphological examination of cell death occurring under various physiological and pathological conditions, Kerr and his colleagues identified a distinct subgroup of cell death characterized by nuclear and cytoplasmic shrinkage, which they termed 'apoptosis'. These authors in their pioneering work made sufficient and significant observations to indicate that apoptosis is an active, inherently programmed cell death involved in the regulation of cell population kinetics. This idea has been supported by ever increasing evidence, and it now seems established that apoptosis is regulated by a cell-intrinsic genetic program and plays critical roles in the development and maintenance of homeostasis of multicellular organisms. Subsequent to the original description of apoptosis, Kerr and colleagues further proposed that cell death can be classified by morphology into two large categories: apoptosis and necrosis, suggesting that necrosis, in contrast to apoptosis, is generally caused in a passive manner by environmental perturbation rather than by factors intrinsic to the cell itself. ${ }^{2}$ This classification has made a crucial contribution, promoting the research of programmed cell death, and thus providing simple and clear-cut visual clues to predict the presence or absence of regulatory programs behind cell death. Unfortunately, however, excessive synonymity and schematism also arose in due course which may carry the risk of neglecting exceptions to a rigid classification, with the risk of oversimplifying. ${ }^{3,4}$ Do all active, programmed cell deaths actually occur by apoptosis? Isn't there active, programmed cell death with necrotic-like morphology having physiological or pathological significance? In this article, we review physiological cell deaths with necrotic morphology occurring in vivo, rapidly accumulating in vitro models of programmed cell death with necrotic-like morphology, and discuss the emerging significance and implications of recognizing and elucidating the regulatory programs operating in necrotic-like cell death.

\section{Physiological cell death with necrotic-like morphology occurring in vivo}

In order to understand the diversity of the mechanisms involved in physiological (or naturally occurring) cell death taking place during the embryogenesis of rat and mouse, Schweichel and Merker ${ }^{5}$ conducted a morphological evaluation of developmental cell death in rat and mouse embryo using an electron microscope. They identified three morphologically distinct groups of physiological cell death (Table 1).

The first type (type 1), always found in isolated cells, was characterized by early condensation of the nucleus and cytoplasm. The dying cells were then fragmented and 
Table 1 Morphological classification of physiological cell death

\begin{tabular}{|c|c|c|c|}
\hline & $\begin{array}{l}\text { Type } 1 \\
\text { (apoptosis) }\end{array}$ & $\begin{array}{l}\text { Type } 2 \\
\text { (autophagic degeneration) }\end{array}$ & $\begin{array}{l}\text { Type } 3 \\
\text { (Non-lysosomal disintegration) }\end{array}$ \\
\hline Nucleus & $\begin{array}{l}\text { Nuclear condensation, pronounced } \\
\text { pyknosis }\end{array}$ & $\begin{array}{l}\text { Pyknosis in some cases, but is neither } \\
\text { prevalent nor striking }\end{array}$ & Late disintegration \\
\hline Cytoplasm & Reduction of volume & Abundant autophagic vacuoles & $\begin{array}{l}\text { General disintegration: dilation of } \\
\text { organelles }\end{array}$ \\
\hline End stage & $\begin{array}{l}\text { Fragmentation, rapid and prominent } \\
\text { phagocytosis by neighboring cells }\end{array}$ & $\begin{array}{l}\text { Fragmentation, late and occasional } \\
\text { phagocytosis by neighboring cells }\end{array}$ & $\begin{array}{l}\text { Fragmentation into very small pieces } \\
\text { without detectable phagocytosis by } \\
\text { neighboring cells }\end{array}$ \\
\hline $\begin{array}{l}\text { Incidence } \\
\text { and location }\end{array}$ & Common, found in isolated dying cells & $\begin{array}{l}\text { Common, found in regions where cells } \\
\text { are removed in toto }\end{array}$ & $\begin{array}{l}\text { Rare (?), found in vacuolated cartilage } \\
\text { during mineralization }\end{array}$ \\
\hline
\end{tabular}

This table summarizes the salient features of the three main types of physiological, developmental cell death according to Schweichel and Merker ${ }^{5}$, Clarke ${ }^{6}$ and Zakeri et al. ${ }^{7}$

were phagocytosed by the neighboring cells. The second type (type 2) was characterized by the early appearance of large inclusions in the cytoplasm derived from autophagic vacuoles or autolysosomes. Later, swelling of cavities was observed and the dying cells were ultimately fragmented and were phagocytosed by the neighboring cells. This type of cell death was found in regions where tissue areas or anlagen of organs were removed in toto. The third type (type 3) was characterized by the swelling of cavities with a membrane border, such as mitochondria, followed by extensive fragmentation of the cells into fragments so small that cell debris can no longer be observed. This type of cell death occurred without the lysosomal system taking part and with recognizable reaction of the neighboring cells, and was observed in regions of vacuolated cartilage during mineralization. Apparently, type 1 physiological cell death is identical to apoptosis described by Kerr et al. ${ }^{1}$ On the contrary, type 2 and type 3 physiological cell deaths, according to morphological criteria, would be classified as necrotic. The validity of this classification proposed by Schweichel and Merker was later confirmed in the worthy reviews of developmental cell death by Clarke $^{6}$ as well as by Zakeri et al. ${ }^{7}$ A literature review revealed that type 1,2 and 3 cell deaths do take place during normal development and that types 1 and 2 are by far the most common forms: similar to type 1 cell death (apoptosis), type 2 cell death characterized by formation of numerous autophagic vacuoles (hence alternatively called 'autophagic degeneration') and by relative paucity of nuclear changes occurred during developmental stages of various species ranging from invertebrates to mammals. There is no doubting the existence of developmental, physiological cell deaths with necrotic-like morphology and almost certainly, such 'developmentally programmed' cell deaths should be under genetic control in a broad sense. An important question to be addressed is whether genetic control of those 'developmentally programmed' cell deaths reside within the cell itself or outside the cell. For instance, assume cells within a tissue fed by a single blood vessel. If the survival of the cells constituting the blood vessel are under cell-intrinsic genetic control and commit suicide at a certain developmental stage, the cells fed by the vessel will die by ischemia closely following the collapse of the feeding vessel. In this case, the death of the cells fed by the vessel is 'developmentally programmed' in the sense that it reproducibly occurs in the same place at the same developmental stage and is indeed genetically regulated, albeit indirectly. Nevertheless, the cell death is not apparently an active, programmed cell death in the sense that it is not regulated by a cell-intrinsic death program. Thus, the identification of type 2 and type 3 cell death provided compelling in vivo evidence of active, programmed cell death with necrotic-like morphology, but the evidence was not conclusive in the absence of direct demonstration that certain genes are involved in their regulation. Clearly, the absence of cellular models has limited the identification of the molecular mechanisms involved in these necrotic-like cell deaths.

\section{Caspase-independent programmed cell death with necrotic-like morphology}

Genetic analysis of 'developmentally programmed' cell death in nematode $\mathrm{C}$. elegans led to the identification of several genes essential for cell-autonomous death regulation, ${ }^{8,9}$ and was the first direct demonstration that 'developmentally programmed' cell death (apoptosis or type 1 cell death in this case) is indeed 'genetically programmed' within the cells. It subsequently turned out that these genes have mammalian counterparts, ${ }^{10-12}$ suggesting conservation of cell death program from worms to mammals. ced-3 is one such gene essential for the execution of programmed cell death, and its protein product has homology to a family of mammalian cysteine proteases called caspases. ${ }^{10,13,14}$ The results of extensive studies at first seemed to support the idea that caspases play general and essential roles in mammalian programmed cell death: ${ }^{15,16}$ caspases were activated in virtually all programmed cell death with apoptotic morphology so far examined, except for a very limited number of cases. ${ }^{17,18}$ Furthermore, inhibition of caspase activities by the use of broad-spectrum (general) caspase inhibitors represented by zVAD-fmk and p35 resulted in the inhibition of apoptosis as assessed by the appearance of apoptotic nuclear morphology and oligonucleosomal DNA fragmentation; a biochemical hallmark of apoptosis. These findings established the idea that caspases are critical determinants of apoptosis at least in terms of morphology, but they did not necessarily imply that the process of caspase activation is the sole determinant of life and death decisions in programmed cell death. Indeed, an increasing number of cases are recently 
reported where the inhibition of caspase activities in mammalian apoptotic systems fails to prevent cell death itself.

Perhaps the first clear demonstration of caspaseindependent programmed cell death is Bax-induced apoptotic cell death. Xiang et al ${ }^{19}$ demonstrated that, although Bax does induce caspase activation and apoptotic cell death in a human leukemic cell line Jurkat, the inhibition of caspase activities inhibited only apoptotic morphology and not cell death itself. Bax-induced Jurkat cell death in the presence of a broad-spectrum caspase inhibitor was characterized by dramatic cytoplasmic vacuolation and only partial chromatin condensation and hence looked 'necrotic'. A similar observation was made using cerebellar granule cells. ${ }^{20}$ Cerebellar granule cells undergo apoptotic cell death in Bax-dependent manner when cultured in medium with low potassium concentration. Again, caspase inhibitors did inhibit typical apoptotic nuclear changes associated with this potassium deprivation-induced cell death, but not cell death itself. Since Baxinduced cell death is inhibitable by broad-spectrum caspase inhibitors at least in some other cell types, ${ }^{21,22}$ these findings suggest that Bax can activate a caspaseindependent program that results in non-apoptotic form of cell death, in a cell type-dependent manner. The ability to trigger non-apoptotic form of cell death was not unique to Bax, as demonstrated by the subsequent observation made by McCarthy et al. ${ }^{23}$ In their report, another Bcl-2 family member Bak, oncogene products such as Myc and E1A, induce typical apoptotic cell death with the evidence of caspase activation. However, in the presence of a broadspectrum caspase inhibitor, they all induced cell death accompanied by cytoplasmic vacuolation and partial chromatin condensation. Importantly, both cell death and associated morphological changes were inhibited by insulin-like growth factor (IGF)-1 and Bcl-2, indicating that cell death is under the regulation of intracellular survival signaling rather than a result of non-specific perturbation of cellular homeostasis. Adding to these observations, it was also demonstrated that, in cytotoxic $T$ lymphocyte (CTL) granule exocytosis-mediated apoptotic cell death of target cells, broad-spectrum caspase inhibitors inhibit apoptotic nuclear morphological changes but not target cell lysis itself. ${ }^{24}$ Furthermore, Hirsch et al ${ }^{25}$ demonstrated that a glucocorticoid receptor agonist dexamethasone, a topoisomerase II inhibitor etoposide, and permeability transition (PT)-inducers such as mCCCP and PPIX induce apoptotic cell death associated with caspase activation in murine thymocytes but, in the presence of a broad-spectrum caspase inhibitor, cell death with a morphology indistinguishable from necrosis (vacuolization, mitochondrial hydropsis, lack of pronounced chromatin condensation). Brunet et $a l^{26}$ also confirmed using a lymphoblastoid cell line that dexamethasone induce, in the presence of a broad-spectrum caspase inhibitor, cell death with only partially condensed chromatin, which was inhibitable by $\mathrm{Bcl}-2$ overexpression. Amarante-Mendes et al ${ }^{27}$ showed that staurosporine, a protein kinase inhibitor, induces caspase activation and apoptotic cell death in Jurkat cells which can be inhibited by the overexpression of $\mathrm{Bcl}-2$ or $\mathrm{Bcr}-\mathrm{Abl}$, but that it induces in the presence of a broad- spectrum caspase inhibitor a 'necrotic-like' cell death characterized by extensive cellular vacuolization. Deas et al $^{28}$ showed that anti-CD2 treatment induces apoptotic cell death in human peripheral $\mathrm{T}$ lymphocytes but induces, in the presence of broad-spectrum caspase inhibitors, cell death characterized by cytoplasmic vacuolization due to dilated endoplasmic reticulum and by partial condensation of nucleus. Also Fas can induce 'necrotic-like' cell death, as demonstrated by Vercammen et al. ${ }^{29}$ Treatment with an agonistic Fas antibody induced apoptotic cell death in L929 murine fibrosarcoma cell line in Fas-dependent manner. Surprisingly, pretreatment of the cells with a caspase inhibitor suppressed apoptotic morphology but facilitated Fas-mediated cell death, and the dying cells assumed a necrotic morphology characterized by intact nucleus and cytoplasmic swelling. Consistent with this, Kawahara et $\mathrm{al}^{30}$ reported that enforced oligomerization of FADD induces cell death with necrotic morphology (swelling of cells without nuclear condensation) in Jurkat cells lacking caspase-8 or in the presence of a broad-spectrum caspase inhibitor, although in Jurkat cells, Fas-induced cell death was completely inhibited by caspase inhibition in contrast to the Fas-induced cell death in L929 cells.

Collectively, these cases demonstrate that quite a broad range of classical (or established) triggers of apoptosis and programmed cell death induce necrotic-like cell death characterized by cytoplasmic vacuolation and by minimal nuclear changes when caspase activities are inhibited. This implies that triggers of programmed cell death can activate caspase-independent cell death programs encoding necrotic (at least non-apoptotic) morphology together with caspase-dependent apoptotic program, and the apparently growing list of caspase-independent programmed cell death strongly suggests that this is not an exceptional, but rather a common event. The demonstration that what has been believed to be programmed cell death has a 'necrotic' face under the mask of 'apoptosis' is quite an impact on current cell death concepts and brings home the inevitable necessity of reassessing 'necrotic-like' cell death as programmed cell death.

Although the above instances were events occurring under a very specific condition whereby caspase activities are artificially inhibited, there are also reports of programmed cell death that originally assumes necrotic (or non-apoptotic) morphology. One such representative case may be tumor necrosis factor (TNF)-induced cytotoxicity. It has been well documented that TNF induces not only apoptotic cell death but also cell death with necrotic morphology depending on the cell type. ${ }^{31}$ Apparently, TNF-induced necrotic-like cell death is not a passive one occurring as a result of non-specific perturbation of cellular homeostasis, because TNF-induced necrotic-like cell death is dependent on the expression of TNF receptors and on the intact downstream intracellular signaling pathway most likely involving generation of reactive oxygen species. ${ }^{31}$ It has been recently demonstrated that this TNF-induced necrotic-like programmed cell death occurs independently of caspase activation. ${ }^{32}$ Another example is glutathione depletion-induced cell death of a neuronal cell line which takes the form of necrosis and yet can be inhibited by $\mathrm{Bcl}-$ 
$2 .^{33,34}$ It remains to be shown whether caspases play a role in this necrotic-like cell death, however. Lowering of intracellular $\mathrm{pH}$ has been shown to effectively kill tumor cells $^{35,36}$ and Zanke et al ${ }^{37}$ recently demonstrated that this intracellular acidification-induced cell death occurs without any morphological changes characteristic of apoptosis or any evidence of caspase activation and that it is resistant to caspase inhibition and Bcl-2 overexpression. Importantly, however, intracellular acidification-induced Jun N-terminal kinase (JNK) activation was essential for this cell death, indicating that it is regulated by JNK-mediated intracellular signaling. It has been recently reported that the expression of PML (promyelocytic leukemia) cellular gene product can induce cell death either with apoptotic or non-apoptotic nuclear morphology depending on the cell type: ${ }^{38,39} \mathrm{PML}-$ induced cell death of rodent fibroblasts ${ }^{39}$ was accompanied by cellular shrinkage, but the dying cells showed neither chromatin condensation nor nuclear fragmentation There was no evidence of caspase activation, and caspase inhibition failed to protect cells from PML-induced death.

Altogether, these observations from in vitro experimental systems strongly argue for the existence of caspaseindependent programs for necrotic-like cell death, and that they can be activated either alone or in concert with the caspase-dependent apoptotic program.

\section{Ras-mediated activation of intracellular signaling leads to necrotic-like cell death with characteristic features of physiological cell death}

As described so far, morphological analysis of developmental cell death in vivo suggested that cell death with necrotic morphology may be active and programmed, and recent reports of caspase-independent cell death in in vitro systems suggested that genetically-regulated programmed cell death may assume necrotic morphology. However, pieces are lacking which would definitively link these in vivo and in vitro lines of evidence for 'necrotic-like' programmed cell death, and consequently, informative correlation has not yet been established between them. In other words, it is not yet clear from the currently available data whether the 'necrotic-like' programmed cell deaths observed in in vitro systems have characteristic features of the necrotic-like physiological cell deaths occurring in vivo, or whether the genes activating necrotic-like programmed cell in vitro also have a role in the regulation of necrotic-like cell deaths in vivo. Here, our recent demonstration that the activation of Ras signaling pathway leads to type 2 physiological cell death (autophagic degeneration), the most common form of developmental cell death with necrotic morphology, may serve as one such important piece. ${ }^{40}$

That activated Ras signaling pathway causes cell death with a unique morphology was found while we were exploring the reason why activating mutation of Ras, which is very common in other tumor types, is extremely rare in glioma. ${ }^{41}$ In an attempt to elucidate the reason, we transiently transfected oncogenically activated $\mathrm{H}$-ras into human glioma cells, and found that activated rastransfected but not control-transfected glioma cells degenerate accompanied by cytoplasmic vacuolation. The results of the transient transfection assays were confirmed by the use of stable glioma transfectants that inducibly express wild-type (wt), activated, and dominant-negative H-Ras proteins by tetracycline removal. Induction of activated Ras (RasV12) in the stable glioma transfectants caused cell death accompanied by cytoplasmic vacuoles as in transient transfection assays. Wt-Ras also induced cell death albeit much less efficiently, and cell death was not induced in control transfectants or transfectants inducibly expressing dominant-negative form of Ras. These results clearly indicated that Ras-mediated activation of intracellular signaling pathway is responsible for cell death induction. In support of this, we have recently found that phosphatidyl inositol 3-OH kinase (PI3K), a physiological effector of Ras, ${ }^{42}$ plays an essential role in this Rasmediated cell death (unpublished observation). Morphological analysis under phase-contrast microscope revealed that, in the early stage of degeneration, the nucleus is intact and that vacuoles and/or granules appear in the perinuclear region (Figure $1 \mathrm{~B}$ ). With the progression of degeneration, the vacuoles grow larger (Figure 1C), and in the late stage, degenerating cells may either remain attached (Figure 1D) or become rounded up or fragment into small pieces (Figure 1E and F). The nuclear morphology is relatively well preserved compared to the prominent cytoplasmic change. These morphological changes associated with activated Ras-mediated cell death were clearly distinct from those of apoptosis. The morphological changes were further examined by electron microscopy. The degenerating cells in the advanced stage showed prominent cytoplasmic change characterized by numerous vacuoles but minimal change in nuclear morphology. Upon closer inspection, some vacuoles appeared to contain cytoplasmic components suggesting that those vacuoles were derived from autophagosomes, and there was no evidence of mitochondrial swelling (Figure 2, Tc (-) Day 5).

These microscopic findings suggested that activated Ras may induce programmed cell death by autophagic degeneration (type 2 cell death) and not by apoptosis. To establish this point, we next examined by electron microscopy the early stage of cell degeneration caused by activated Ras, and we identified primary activation (increase in number and size) of lysosomal apparatus containing electron-dense material (Figure 2, Tc (-) Day 1.5), a characteristic feature distinguishing autophagic degeneration from other types of physiological cell death. ${ }^{5,7}$ We also examined the degenerating cells by immunocytochemistry using lysosomal membrane markers and confirmed that most of the vacuoles are derived from lysosome. ${ }^{40}$ Furthermore, when involvement of caspases was examined, this activated Ras-induced cell death was neither accompanied by caspase activation nor inhibited by broad-spectrum caspase inhibitors. ${ }^{40}$ Collectively, the results indicated that: (i) activation of Ras signaling induces a caspase-independent programmed cell death, (ii) the cell death corresponds to autophagic degeneration (type 2 cell death) observed during normal development. These results therefore provide evidence that autophagic degeneration is under a cell-intrinsic genetic control, molecularly distinct from that of apoptosis. 
Recognizing active, programmed cell death among cell death with necrotic morphology: its necessity and significance

Under 'apoptosis vs necrosis' classification, cell death is generally divided into two groups: (i) active, programmed cell death having apoptotic morphology, and (ii) passive, uncontrolled cell death having necrotic morphology. However, accumulating in vivo and in vitro findings presented in the literature as well as in this article, apparently suggest the existence of exceptions to this classification, dictating reassessment of 'necrotic cell death' as a heterogeneous entity containing both active and passive cell deaths (Figure 3 ). At least, type 2 cell death (autophagic degeneration),

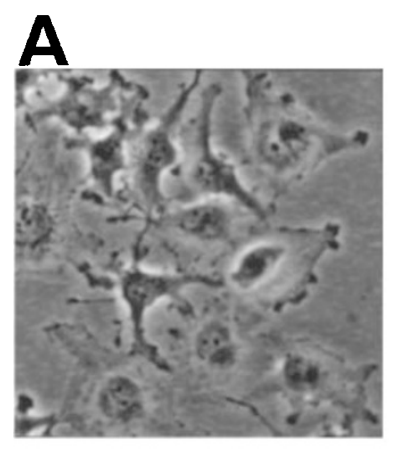

\section{D}

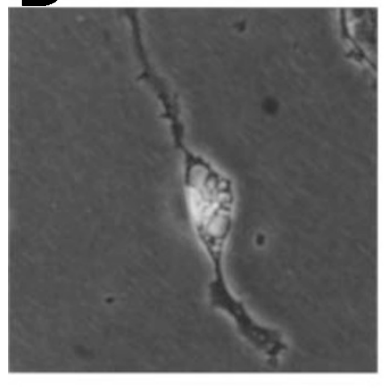

B
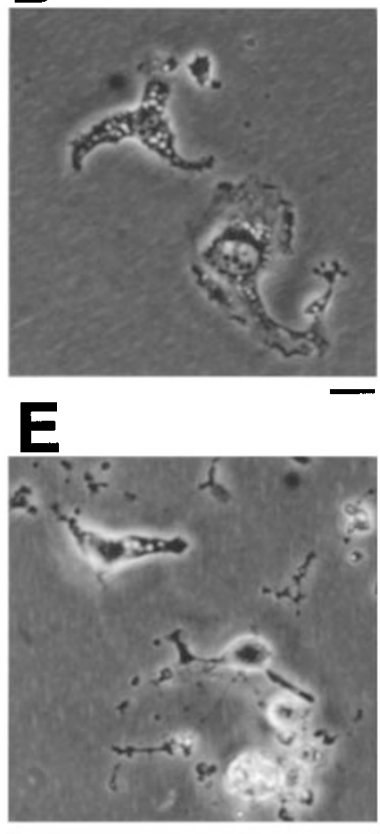

C
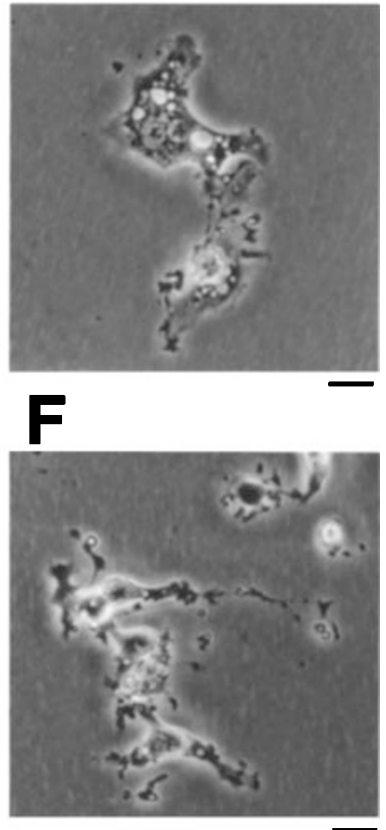

Figure 1 Morphology of Ras-mediated U251 human glioma cell death under phase-contrast microscope. U251TA-RasV12 cells are a stable U251 transfectant which inducibly expresses activated H-Ras (RasV12) by tetracycline removal. (A) U251TA-RasV12 stable glioma transfectant cultured in the presence of tetracycline (activated Ras expression suppressed). (B-F) U251TA-RasV12 cells were cultured in the absence of tetracycline (activated Ras expression induced) for 2 days (B), 3 days (C), and 4 days (D-F). Scale bar $=25 \mu \mathrm{m}$

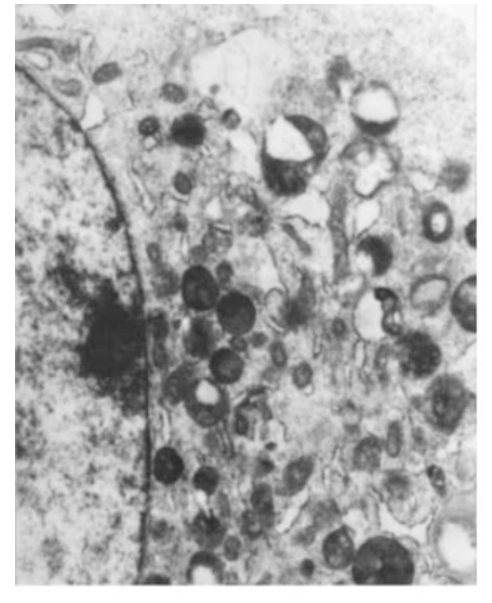

Tc(-), Day 1.5

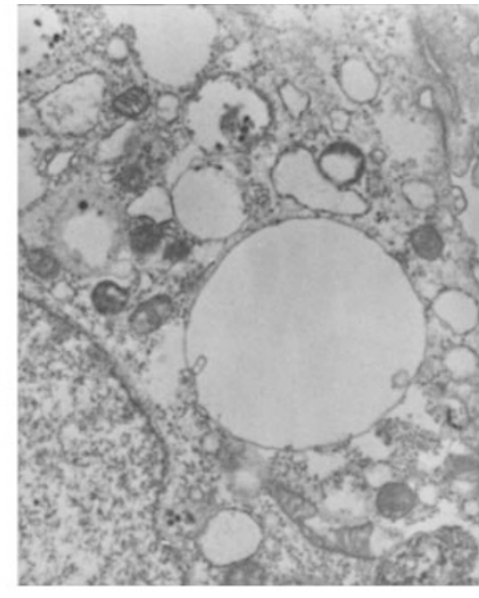

Tc(-), Day 5

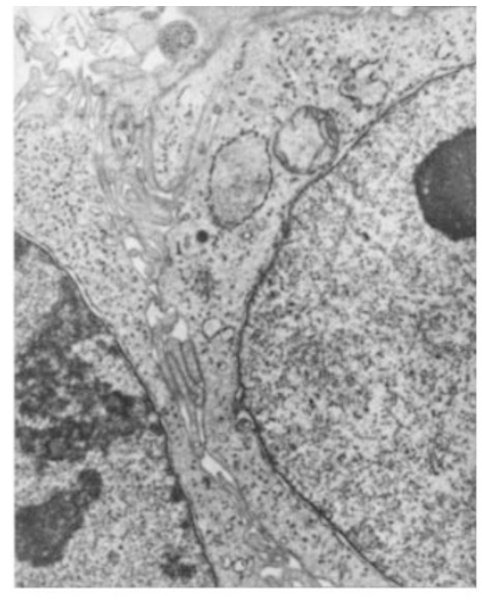

Tc(+)

Figure 2 Transmission electron microscopic analysis of Ras-mediated cell death. U251TA-RasV12 cells were cultured in the absence of tetracycline (activated Ras expression induced) for 1.5 days (Tc(-), Day 1.5), 5 days (Tc(-), Day 5), or in the presence of tetracycline (activated Ras expression suppressed) (Tc(+)). Scale bar $=1 \mu \mathrm{m}$ 
which would be categorized into 'necrosis' under 'apoptosisnecrosis' classification, needs to be distinguished from other cell deaths showing necrotic morphology. The existence of type 2 cell death itself was once questioned, and it was claimed that what appears to be type 2 cell death is actually a cell phagocytosing apoptotic cells (bodies). ${ }^{2}$ But now, our in vitro data indicate that type 2 cell death does exist as an active, programmed cell death having a distinct regulatory mechanism from that of apoptosis. On the other hand, whereas most of programmed cell deaths with necrotic morphology seem to be independent of caspase activation as shown above, there is also a report of cell death with necrotic morphology in which caspases play a regulatory role. ${ }^{43,44}$ Thus, programmed cell death with necrotic morphology may be further divided into two subgroups according to the involvement of caspases in cell death regulation.

The significance and importance of recognizing active, programmed cell deaths among cell deaths with necrotic morphology and elucidating the death programs involved (which is most likely caspase-independent) will be most apparent in the medical aspect of cell death research. Reflecting the fact that programmed cell death plays a critical role in the maintenance of tissue homeostasis, dysregulation of programmed cell death has been demonstrated to result in various pathological conditions. ${ }^{45}$ For instance, neurodegenerative disorders are regarded as a representative of diseases caused by excessive programmed cell death. Great efforts have been made to identify apoptotic processes in neurodegenerative disorders with the intention to control disease progression by inhibiting apoptosis. However, conclusive evidence is yet to be obtained that apoptosis is solely responsible for the excessive cell death observed in these diseases. ${ }^{46,47}$ Intriguingly, postmortem electron-microscopic analysis of human brain affected with neurodegenerative diseases such as Alzheimer's and Parkinson's diseases revealed that the dying neurons showed morphological changes compatible with autophagic degeneration. ${ }^{48-50}$ Such observations suggest the possibility that caspase-independent cell death program may be operating in those diseases, and in that case, elucidation of the caspaseindependent cell death program is essential for rescuing neurons from pathological cell death. Even in diseases where the affected cells have been shown to die with 'apoptotic' morphology, one cannot exclude the possibility that caspase-independent cell death program is operating in concert with caspase-dependent apoptosis program, as demonstrated by the instances of caspase-independent cell death reviewed in this article. In such cases, inhibition of apoptosis by caspase inhibition would only delay, but not prevent, the progression of diseases. On the other hand, cancer is a representative of diseases caused by inappropriate survival of preneoplastic cells that would be normally disposed through activation of cell death program. Activation of a suicide program in tumor cells should therefore be a straightforward approach of cancer therapy, and attempts have been made to kill tumor cells via

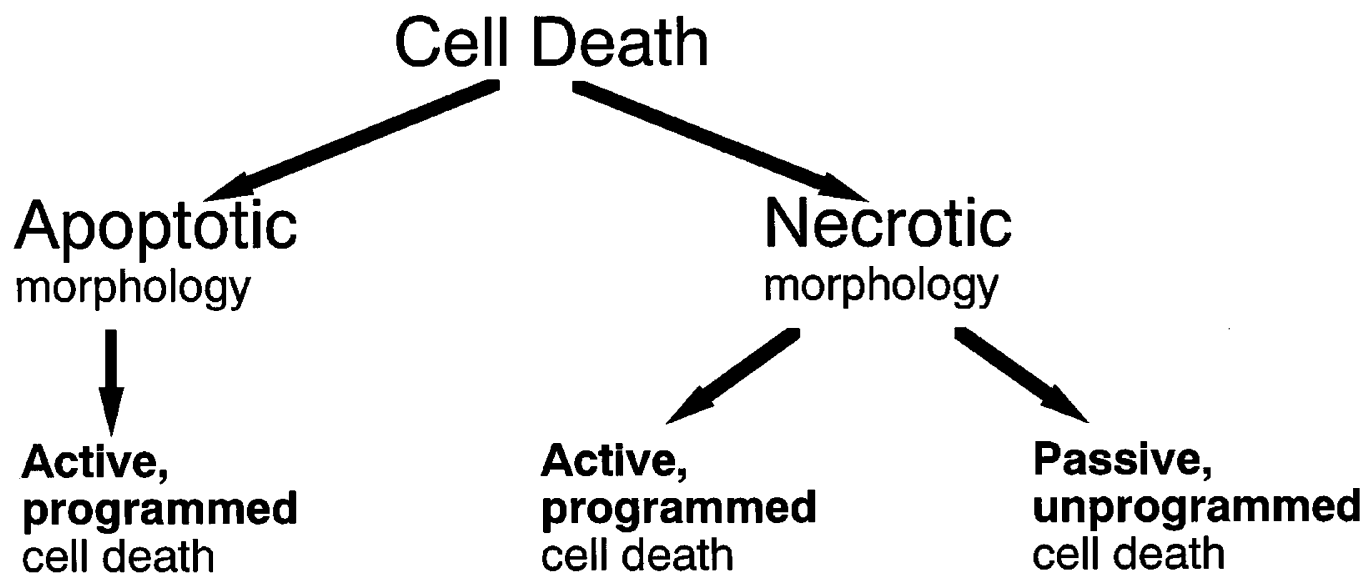

(Type 1 physiological

("Necrotic-like" programmed cell death.

(Classical necrosis) cell death) Includes type 2 physiological cell death)

\section{Passive cell death}

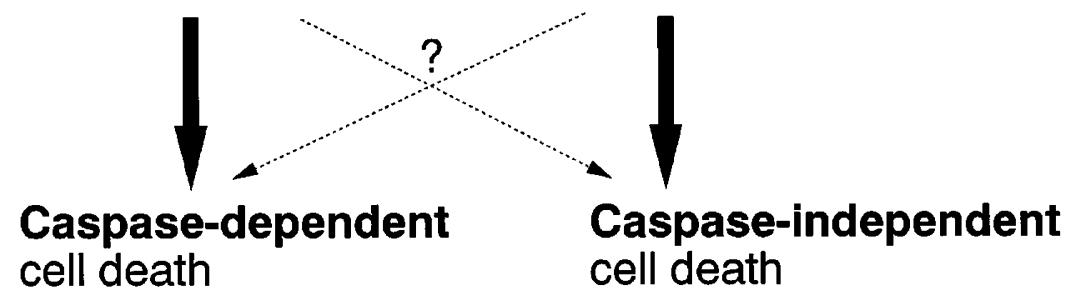

Figure 3 Morphological and functional classifications of cell death proposed in this article. Cell death is in general divided into two groups according to their morphology, 'apoptotic' and 'necrotic'. It can be further classified into 'programmed' and 'unprogrammed' according to the presence or absence of underlying regulatory mechanisms, and 'programmed' cell death is subdivided according to its dependence on caspases 
apoptosis. However, it needs to be remembered that cancer is so often made up of selected population of cells that have gained resistance against apoptosis. ${ }^{51,52}$ In this respect, if tumor cells have cell death programs other than 'apoptotic' program, activation of such programs would be quite beneficial and become a promising therapeutic approach that complements apoptosis-based therapies. Thus, identifying active, programmed cell deaths among cell deaths with necrotic morphology that would otherwise have been dismissed as passive, unprogrammed ones, together with the elucidation of their underlying mechanisms, is not only important for the comprehensive understanding of programmed cell death itself but has potential practical implications in the treatment of human diseases.

\section{Concluding remarks}

With the recognition of 'necrotic-like' programmed cell death, molecular study of 'necrotic death program' has just emerged with only a handful of information but with plentiful possibilities. Much remains to be done before this field is widely accepted as the current apoptosis research is. For instance, it would be important to demonstrate that factors which have been shown to induce necrotic-like cell death in in vitro systems are involved in necrotic-like cell deaths occurring under physiological and pathological conditions. Similarly important is further identification of genes or factors that are essential for necrotic-like cell death in vivo as well as in in vitro systems. Although we have mainly discussed necrotic-like programmed cell death in mammalian systems, no one would cast doubt on the power of genetic approaches utilizing worms and flies for the above purposes, as exemplified by the apoptosis research. Indeed, there are some worm models of necrotic-like cell death, ${ }^{53-58}$ and it has been recently reported that adenylyl cyclase is essential for $G$ protein hyperactivation-induced necrotic-like neuronal degeneration in Caenorhabditis elegans. ${ }^{59,60}$ Developing animal models of necrotic-like cell death would thus be of great help in advancing our knowledge of molecular regulation of necrotic-like cell death as it was for apoptotic cell death.

Finally, what is most vital for the promotion of this newborn research field is that researchers become fully aware of the existence of 'necrotic-like' programmed cell death and have keen intention to elucidate the regulatory mechanisms behind their 'necrotic' faces which might have been neglected for a long time just because they look 'necrotic'.

\section{Acknowledgments}

The authors thank Drs. Yohji Nagashima and Midori Yoshida for electron microscopy, and Dr. Gerry Melino for critical reading of the manuscript. This work was supported by a Grant-in-Aid from the Ministry of Health and Welfare of Japan for the 2nd-term Comprehensive 10-Year Strategy for Cancer Control and by a grant from the Ministry of Health and Welfare of Japan to $Y$. Kuchino and by grants from the Ministry of Education, Science and Culture of Japan for cancer research to Y. Kuchino and C. Kitanaka.

\section{References}

1. Kerr JFR, Wyllie AH and Currie AR (1972) Apoptosis: a basic biological phenomenon with wide-ranging implications in tissue kinetics. Br. J. Cancer 26: $239-257$

2. Wyllie AH, Kerr JFR and Currie AR (1980) Cell death: the significance of apoptosis. Int. Rev. Cytol. 68: 251-306

3. Schwartz LM, Smith SW, Jones ME and Osborne BA (1993) Do all programmed cell deaths occur via apoptosis? Proc. Natl. Acad. Sci. USA 90: 980-984

4. Schwartz LM (1995) The faces of death. Cell Death Differ. 2: 83-85

5. Schweichel JU and Merker HJ (1973) The morphology of various types of cell death in prenatal tissues. Teratology 7: 253-266

6. Clarke PGH (1990) Developmental cell death: morphological diversity and multiple mechanisms. Anat. Embryol. 181: 195-213

7. Zakeri Z, Bursch W, Tenniswood M and Lockshin RA (1995) Cell death: programmed, apoptosis, necrosis or other? Cell Death Differ. 2: 87-96

8. Ellis HM and Horvitz HR (1986) Genetic control of programmed cell death in the nematode C. elegans. Cell 44: 817-829

9. Ellis RE, Yuan JY and Horvitz HR (1991) Mechanisms and functions of cell death. Annu. Rev. Cell Biol. 7: 663-698

10. Miura M, Zhu H, Rotello R, Hartwieg EA and Yuan J (1993) Induction of apoptosis in fibroblasts by IL-1 $\beta$-converting enzyme, a mammalian homolog of the $\mathrm{C}$. elegans cell death gene ced-3. Cell 75: 653-660

11. Hengartner MO and Horvitz HR (1994) C. elegans cell survival gene ced-9 encodes a functional homolog of the mammalian proto-oncogene bcl-2. Cell 76: $665-676$

12. Zou H, Henzel WJ, Liu X, Lutschg A and Wang X (1997) Apaf-1, a human protein homologous to $\mathrm{C}$. elegans CED-4, participates in cytochrome c-dependent activation of caspase-3. Cell 90: 405-413

13. Yuan J, Shaham S, Ledoux S, Ellis HM and Horvitz HR (1993) The C. elegans cell death gene ced-3 encodes a protein similar to mammalian interleukin-1 $\beta$ converting enzyme. Cell 75: 641-652

14. Alnemri ES, Livingston DJ, Nicholson DW, Salvesen G, Thornberry NA, Wong WW and Yuan J (1996) Human ICE/CED-3 protease nomenclature. Cell 87: 171

15. Kumar S and Lavin MF (1996) The ICE family of cysteine proteases as effectors of cell death. Cell Death Differ. 3: 255-268

16. Jacobson MD, Weil M and Raff MC (1997) Programmed cell death in animal development. Cell 88: 347-354

17. Adjei PN, Kaufmann SH, Leung W-Y, Mao F and Gores GJ (1996) Selective induction of apoptosis in Hep 3B cells by topoisomerase I inhibitors: evidence for a protease-dependent pathway that does not activate cysteine protease p32. J. Clin. Invest. 98: 2588-2596

18. Lavoie JN, Nguyen M, Marcellus RC, Branton PE and Shore GC (1998) E4orf4, a novel adenovirus death factor that induces p53-independent apoptosis by a pathway that is not inhibited by zVAD-fmk. J. Cell Biol. 140: 637-645

19. Xiang J, Chao DT and Korsmeyer SJ (1996) Bax-induced cell death may not require interleukin $1 \beta$-converting enzyme-like proteases. Proc. Natl. Acad. Sci. USA 93: $14559-14563$

20. Miller TM, Moulder KL, Knudson CM, Creedon DJ, Deshmukh M, Korsmeyer SJ and Johnson Jr EM (1997) Bax deletion further orders the cell death pathway in cerebellar granule cells and suggests a caspase-independent pathway to cell death. J. Cell Biol. 139: 205-217

21. Deveraux QL, Takahashi R, Salvesen GS and Reed JC (1997) X-linked IAP is a direct inhibitor of cell-death proteases. Nature 388: 300-304

22. Kitanaka C, Namiki T, Noguchi K, Mochizuki T, Kagaya S, Chi S, Hayashi A, Asai A, Tsujimoto $Y$ and Kuchino $Y$ (1997) Caspase-dependent apoptosis of COS-7 cells induced by Bax overexpression: differential effects of Bcl-2 and Bcl-xL on Bax-induced caspase activation and apoptosis. Oncogene 15: 1763-1772

23. McCarthy NJ, Whyte MK, Gilbert CS and Evan GI (1997) Inhibition of Ced-3/ICErelated proteases does not prevent cell death induced by oncogenes, DNA damage, or the Bcl-2 homologue Bak. J. Cell Biol. 136: 215-227

24. Sarin A, Williams MS, Alexander-Miller MA, Berzofsky JA, Zacharchuk CM and Henkart PA (1997) Target cell lysis by CTL granule exocytosis is independent of ICE/Ced-3 family proteases. Immunity 6: 209-215

25. Hirsch T, Marchetti P, Susin SA, Dallaporta B, Zamzami N, Marzo I, Geuskens M and Kroemer G (1997) The apoptosis-necrosis paradox. Apoptogenic proteases activated after mitochondrial permeability transition determine the mode of cell death. Oncogene 15: 1573-1581 
26. Brunet CL, Gunby RH, Benson RSP, Hickman JA, Watson AJM and Brady G (1998) Commitment to cell death measured by loss of clonogenicity is separable from the appearance of apoptotic markers. Cell Death Differ. 5: 107-115

27. Amarante-Mendes GP, Finucane DM, Martin SJ, Cotter TG, Salvesen GS and Green DR (1998) Anti-apoptotic oncogenes prevent caspase-dependent and independent commitment for cell death. Cell Death Differ. 5: 298-306

28. Deas O, Dumon C, MacFarlane M, Rouleau M, Hebib C, Harper F, Hirsch F, Charpentier B, Cohen GM and Senik A (1998) Caspase-independent cell death induced by anti-CD2 or staurosporin in activated human peripheral $T$ lymphocytes. J. Immunol. 161: 3375-3383

29. Vercammen D, Brouckaert G, Denecker G, Van de Craen M, Declercq W, Fiers W and Vandenabeele $P$ (1998) Dual signaling of the Fas receptor: initiation of both apoptotic and necrotic cell death pathways. J. Exp. Med. 188: 919-930

30. Kawahara A, Ohsawa Y, Matsumura H, Uchiyama Y and Nagata S (1998) Caspase-independent cell killing by Fas-associated protein with death domain. J. Cell Biol. 143: 1353-1360

31. Schulze-Osthoff K, Krammer PH and Droge W (1994) Divergent signalling via APO-1/Fas and the TNF receptor, two homologous molecules involved in physiological cell death. EMBO J. 13: 4587-4596

32. Vercammen D, Beyaert R, Denecker G, Goossens V, Van Loo G, Declercq W, Grooten J, Fiers W and Vandenabeele P (1998) Inhibition of caspases increases the sensitivity of $L 929$ cells to necrosis mediated by tumor necrosis factor. J. Exp. Med. 187: 1477-1485

33. Kane DJ, Sarafian TA, Anton R, Hahn H, Gralla EB, Valentine JS, Ord T and Bredesen DE (1993) Bcl-2 inhibition of neural death: decreased generation of reactive oxygen species. Science 262: $1274-1277$

34. Kane DJ, Ord T, Anton R and Bredesen DE (1995) Expression of bcl-2 inhibits necrotic neural cell death. J. Neurosci. Res. 40: 269-275

35. Maidorn RP, Cragoe Jr EJ and Tannock IF (1993) Therapeutic potential of analogues of amiloride: inhibition of the regulation of intracellular $\mathrm{pH}$ as a possible mechanism of tumour selective therapy. Brit. J. Cancer 67: 297-303

36. Yamagata M and Tannock IF (1996) The chronic administration of drugs that inhibit the regulation of intracellular $\mathrm{pH}$ : in vitro and anti-tumour effects. Brit. J. Cancer 73: $1328-1334$

37. Zanke BW, Lee C, Arab S and Tannock IF (1998) Death of tumor cells after intracellular acidification is dependent on stress-activated protein kinases (SAPK/JNK) pathway activation and cannot be inhibited by Bcl-2 expression or interleukin-1 $\beta$-converting enzyme inhibition. Cancer Res. 58: 2801-2808

38. Le XF, Vallian S, Mu ZM, Hung MC and Chang KS (1998) Recombinant PML adenovirus suppresses growth and tumorigenicity of human breast cancer cells by inducing G1 cell cycle arrest and apoptosis. Oncogene 16: 1839-1849

39. Quignon F, De Bels F, Koken M, Feunteun J, Ameisen J-C and de The H (1998) $\mathrm{PML}$ induces a novel caspase-independent death process. Nature Genet. 20: 259-265

40. Chi S, Kitanaka C, Noguchi K, Mochizuki T, Nagashima Y, Shirouzu M, Fujita H, Yoshida M, Chen W, Asai A, Himeno M, Yokoyama S and Kuchino Y (1999) Oncogenic Ras triggers cell suicide through the activation of a caspaseindependent cell death program in human cancer cells. Oncogene 18: 2281 2290

41. BosJL (1989) ras oncogenes in human cancer: a review. CancerRes. 49:46824689
42. Vojtek $A B$ and Der CJ (1998) Increasing complexity of the Ras signaling pathway. J. Biol. Chem. 273: 19925-19928

43. Shimizu S, Eguchi $Y$, Kamiike W, Waguri S, Uchiyama $Y$, Mastusda $\mathrm{H}$ and Tsujimoto Y (1996) Retardation of chemical hypoxia-induced necrotic cell death by Bcl-2 and ICE inhibitors: possible involvement of common mediators in apoptotic and necrotic signal transduction. Oncogene 12: 2045-2050

44. Tsujimoto $Y$ (1997) Apoptosis and necrosis: intracellular ATP level as a determinant for cell death modes. Cell Death Differ. 4: 429-434

45. Thompson CB (1995) Apoptosis in the pathogenesis and treatment of disease. Science 267: 1456 - 1462

46. Stefanis L, Burke RE and Greene LA (1997) Apoptosis in neurodegenerative disorders. Curr. Opin. Neurol. 10: 299-305

47. Barinaga M (1998) Is apoptotis key in Alzheimer's disease? Science 281:13031304

48. Cataldo AM, Hamilton DJ and Nixon RA (1994) Lysosomal abnormalities in degenerating neurons link neuronal compromise to senile plaque development in Alzheimer disease. Brain Res. 640: 68-80

49. Cataldo AM, Barnett JL, Berman SA, Li J, Quarless S, Bursztajn S, Lippa C and Nixon RA (1995) Gene expression and cellular content of cathepsin D in Alzheimer's disease brain: evidence for early up-regulation of the endosomallysosomal system. Neuron 14: 671-680

50. Anglade P, Vyas S, Javoy-Agid F, Herrero MT, Michel PP, Marquez J, MouattPrigent A, Ruberg M, Hirsch EC and Agid Y (1997) Apoptosis and autophagy in nigral neurons of patients with Parkinson's disease. Histol. Histopathol. 12: 2531

51. Williams GT (1991) Programmed cell death: apoptosis and oncogenesis. Cell 65 : 1097-1098

52. Fisher DE (1994) Apoptosis in cancer therapy: crossing the threshold. Cell 78: $539-542$

53. Chalfie M and Wolinsky E (1990) The identification and suppression of inherited neurodegeneration in Caenorhabditis elegans. Nature 345: 410-416

54. Driscoll M and Chalfie M (1991) The mec-4 gene is a member of a family of Caenorhabditis elegans genes that can mutate to induce neuronal degeneration. Nature 349: 588-593

55. Huang M and Chalfie M (1994) Gene interactions affecting mechanosensory transduction in Caenorhabditis elegans. Nature 367: 467-470

56. Driscoll M (1996) Cell death in C. elegans: molecular insights into mechanisms conserved between nematodes and mammals. Brain Pathol. 6: 411-425

57. Hall DH, Gu G, Garcia-Anoveros J, Gong L, Chalfie M and Driscoll M (1997) Neuropathology of degenerative cell death in Caenorhabditis elegans. J. Neurosci. 17: 1033-1045

58. Korswagen HC, Park JH, Ohshima Y and Plasterk RHA (1997) An activating mutation in a Caenorhabditis elegans $G$ protein induces neuronal degeneration. Genes Dev. 11: 1493-1503

59. Korswagen HC, van der Linden AM and Plasterk RHA (1998) G protein hyperactivation of the Caenorhabditis elegans adenylyl cyclase SGS- 1 induces neuronal degeneration. EMBO J. 17: 5059-5065

60. Berger AJ, Hart AC and Kaplan JM (1998) Gas-induced neurodegeneration in Caenorhabditis elegans. J. Neurosci. 18: 2871-2880 